\title{
Lipid raft localization of epidermal growth factor receptor alters matrix metalloproteinase-1 expression in SiHa cells via the MAPK/ERK signaling pathway
}

\author{
ZONGFENG ZHANG, LINA WANG, JUAN DU, YUANBO LI, \\ HUILUN YANG, CHENXI LI, HUI LI and HAIYANG HU \\ Department of Obstetrics and Gynecology, Second Affiliated Hospital, \\ Harbin Medical University, Harbin, Heilongjiang 150086, P.R. China
}

Received May 24, 2015; Accepted October 3, 2016

DOI: $10.3892 / \mathrm{ol} .2016 .5307$

\begin{abstract}
Matrix metalloproteinase-1 (MMP-1) has been identified as an important participant in tumor invasion, metastasis and angiogenesis. The purpose of the present study was to investigate the effects of epidermal growth factor receptor (EGFR) localization to lipid rafts on signaling pathways involved in the regulation of MMP-1 expression in SiHa cells, a cervical cancer cell line. EGFR activation by EGF specifically induced MMP-1 expression at both the messenger RNA and protein levels. Additionally, it was observed that EGFR localized to lipid rafts, and that the redistribution of EGFR induced by lipid raft disruption strengthened EGF-induced MMP-1 expression. MMP-1 induction was blocked by the mitogen-activated protein kinase (MAPK) kinase inhibitors PD98059 and U0126. Our results suggested that lipid rafts provide a platform to inhibit EGFR regulation of MMP-1 in $\mathrm{SiHa}$ cells through the MAPK/extracellular signal-regulated kinase signaling pathway.
\end{abstract}

\section{Introduction}

Cancer of the cervix occurs in $\sim 500,000$ women worldwide each year, with an increased prevalence in relatively young

Correspondence to: Professor Zongfeng Zhang, Department of Obstetrics and Gynecology, Second Affiliated Hospital, Harbin Medical University, 246 Xuefu Road, Harbin, Heilongjiang 150086, P.R. China

E-mail: viaac1973@163.com

Abbreviations: MMPs, matrix metalloproteinases; EGFR, epidermal growth factor receptor; ERK, extracellular signal-regulated kinase; MAPK, mitogen-activated protein kinase; PI3-K, phosphatidylinositol 3-kinase; JNK, c-Jun N-terminal kinase; M $\beta C D$, methyl- $\beta$-cyclodextrin; HR-HPVs, high-risk human papillomaviruses

Key words: lipid raft, epidermal growth factor receptor, extracellular signal-regulated kinase, matrix metalloproteinase-1 women (1). An essential feature of the progression of cervical cancer is stromal invasion, which is the result of complex, multifactorial processes involving matrix metalloproteinases (MMPs), a closely related multigene family of zinc-dependent proteolytic enzymes (2). Among MMPs, MMP-1 (collagenase-1), together with MMP-8 and MMP-13, are known as the interstitial collagenases, and are capable of initiating the degradation of fibrillar-type collagens by cleaving their $\mathrm{N}$-terminus (3). MMP-1 presents specific substrates for collagenases I, II, III, VII, VIII and X as well as for proteoglycans (4,5). Increased MMP-1 expression has been associated with the incidence or invasiveness of various types of cancer, including colorectal, esophageal, pancreatic, gastric and breast cancer (6-9). Recent studies have demonstrated that the collagenase activity of MMP-1 may be associated with tumor cell invasion and increased angiogenesis in xenograft models of malignant melanomas such as breast cancer (9). Furthermore, MMP-1 has also been shown to liberate signaling molecule precursors, including epidermal growth factor (EGF)-like ligands and transforming growth factor- $\beta$, from cell surfaces or the extracellular matrix (ECM) $(10,11)$.

The EGF receptor (EGFR) has been shown to be expressed at moderate-to-high levels in carcinoma of the cervix in addition to a wide variety of other solid tumors (12). Furthermore, an increase in EGFR expression with an increase in disease stage has been observed, and EGFR expression has been associated with poor prognosis (13). EGFR is a receptor tyrosine kinase whose function has been implicated in regulating nuclear and cytoplasmic events, including proliferation, survival, differentiation and migration. Autophosphorylation of EGFR to phosphorylated (phospho)-EGFR leads to the activation of two downstream pathways: The mitogen-activated protein kinase (MAPK) pathway and the phosphatidylinositol 3-kinase (PI3-K)/AKT pathway. The major MAPK pathways consist of extracellular signal-regulated kinase (ERK)1/2, p38 and c-Jun N-terminal kinase (JNK) (14). The sub-cellular localization of EGFR determines the signaling pathways stimulated by EGFR activation (15). The most well-known localization of EGFR is to lipid rafts, which are enriched in cholesterol, sphingolipids and gangliosides, and are less fluid than the surrounding bulk plasma membrane (16). Lipid 
rafts may act as platforms to facilitate the crosstalk between different components of various signaling pathways that are in close proximity or as sequestering regions to prevent the association of components of signaling events $(17,18)$. However, the effect of EGFR localization to lipid rafts is not well understood. While it has been noted that lipid raft localization of EGFR inhibits ligand binding and subsequent downstream signaling $(19,20)$, other studies have shown that lipid rafts promote EGFR signaling (21).

Our analyses previously demonstrated that EGFR regulates melatonin receptor type 1A (MT1)-MMP and MMP-2 synthesis in the SiHa cervical cancer cell line via both the PI3-K/AKT and MAPK/ERK pathways (22). However, the effects of EGFR localization to lipid rafts on signaling pathways involved in the regulation of MMP-1 expression are unknown. In the present study, it was concluded that lipid raft localization of EGFR alters MMP-1 expression in SiHa cells via the MAPK/ERK signaling pathway.

\section{Materials and methods}

Cell culture. SiHa cells were purchased from the Chinese Academy of Sciences cell bank (Shanghai, China). Cells were plated in 6-well plates at $\sim 2 \times 10^{6}$ viable cells per well in $1 \mathrm{ml}$ of Dulbecco's modified Eagle medium (Solarbio Science and Technology Co., Ltd., Beijing, China) containing $10 \%$ fetal bovine serum (Zhejiang Tianhang Biotechnology Co., Ltd., Hangzhou, China), and cultured at $37^{\circ} \mathrm{C}$ in an atmosphere of $5 \% \mathrm{CO}_{2}$ and $95 \%$ air. Cells were allowed to attach for $24 \mathrm{~h}$ and then incubated in serum-free medium for 16-18 h. Subsequently, the cells were treated with EGF (PeproTech Inc., Rocky Hill, NJ, USA) in the presence or absence of methyl- $\beta$-cyclodextrin (MßCD; 0.5 nM; Sigma-Aldrich; Merck Millipore, Darmstadt, Germany), cholesterol (10 $\mu \mathrm{M}$; Sigma-Aldrich; Merck Millipore) and inhibitors of EGFR (ZD1839; $10 \mathrm{nM}$; AstraZeneca, London, UK), PI3-K (LY294002; 20 nM; and wortmannin; $5 \mathrm{nM}$ ), MAPK kinase (MEK) (PD98059; $20 \mathrm{nM}$; and U0126; $10 \mathrm{nM}$ ), p38 (SB203580; $10 \mathrm{nM}$ ) and JNK (SP600125; $10 \mathrm{nM}$; all Sigma-Aldrich; Merck Millipore) for $1 \mathrm{~h}$ prior to exposure to EGF. Cells were harvested after incubation with EGF for the indicated length of time.

Reverse transcription-quantitative polymerase chain reaction (RT- $q P C R)$. Total cellular RNA was extracted using TRIzol reagent (Invitrogen; Thermo Fisher Scientific, Inc., Waltham, MA, USA) according to the manufacturer's protocol. Total RNA was reverse-transcribed into single strand complementary DNA using the First Strand cDNA Synthesis kit (Takara Biotechnology Co., Ltd., Dalian, China). qPCR was performed using the Power SYBR ${ }^{\circledR}$ Green PCR Master Mix on an ABI 7500 Real Time PCR System (both Applied Biosystems; Thermo Fisher Scientific, Inc.). The cycling conditions were as follows: $95^{\circ} \mathrm{C}$ for $10 \mathrm{~min}$, followed by 40 cycles at $95^{\circ} \mathrm{C}$ for $15 \mathrm{sec}, 60^{\circ} \mathrm{C}$ for $30 \mathrm{sec}$ and $72^{\circ} \mathrm{C}$ for $30 \mathrm{sec}$. The sequences of the RT primers were as follows: Human (h) MMP-1 (346 bp) sense 5'-CATCGTGTTGCGGCTCAT-3' and antisense 5'-GCCCAT TTGGCAGTTGTG-3' (59.4 $\left.{ }^{\circ} \mathrm{C}\right)$; h tissue inhibitor of matrix metalloproteinase-1 (TIMP-1) (285 bp) sense 5'-TCCTGTTGT TGCTGTGGCTGAT-3' and antisense 5'-ACTCCTCGCTGC GGTTGTG-3' (59.4 ${ }^{\circ} \mathrm{C}$ ); and hGAPDH (502 bp) sense 5'-GGT
GAAGGTCGGTGTGAACGGATTT-3' and antisense 5'-AAT GCCAAAGTTGTCATGGATGACC-3' $\left(58.0^{\circ} \mathrm{C}\right)$. The relative expression level was calculated using the $\Delta \Delta \mathrm{Cq}$ method (23).

Biochemical lipid raft isolation. Biochemical lipid raft isolation was performed following established protocols (24). Briefly, cells in 6-well plates were scraped in buffer $[20 \mathrm{mM}$ Tris (pH 7.8), $250 \mathrm{mM}$ sucrose, $1 \mathrm{mM} \mathrm{MgCl}, 1 \mathrm{mM} \mathrm{CaCl} \mathrm{m}_{2}$ and $100 \mathrm{M}$ sodium orthovanadate] and then lysed in buffer containing $1 \mathrm{X}$ protease inhibitor cocktail (Solarbio Science and Technology Co., Ltd.) by passing through a 22-gauge needle (Sigma-Aldrich; Merck Millipore) 20 times. Lysates were centrifuged as described (24), and the first and second post-nuclear supernatants were combined and frozen at $-20^{\circ} \mathrm{C}$. Samples were thawed and combined with an equal volume of 50\% Opti-Prep (Greiner Bio-One, Monroe, NC, USA), and 0-20\% Opti-Prep gradient was then applied. Gradients were centrifuged for $90 \mathrm{~min}$ at 52,000 x $g$ and then fractionated into 12 0.74-ml fractions. Fractions were either dot blotted with cholera toxin subunit B-horseradish peroxidase (1:100 dilution; cat. no. C34780; Invitrogen; Thermo Fisher Scientific, Inc.) for $30 \mathrm{~min}$ on ice, and then for $20 \mathrm{~min}$ at $37^{\circ} \mathrm{C}$, to determine monosialotetrahexosylganglioside (GM1) expression or subjected to western blotting with antibodies.

Western blotting. Cells were lysed in radioimmunoprecipitation assay lysis buffer plus protease inhibitors (Solarbio Science and Technology Co., Ltd.) and phosphatase inhibitor cocktail (Sigma-Aldrich; Merck Millipore). The concentration of protein in each sample was measured with a BCA Protein Assay kit (Pierce; Thermo Fisher Scientific, Inc.). Aliquots of protein $(40 \mu \mathrm{g})$ were subjected to western blotting as described previously (25). The following primary antibodies were used: Anti-EGFR (1:1,000 dilution; cat. no. 2239), anti-phospho-EGFR (1:1,000 dilution; cat. no. 2641), anti-AKT (1:2,000 dilution; cat. no. 2920), anti-phospho-AKT (Ser473) (1:1,000 dilution; cat. no. 12694), anti-ERK1/2 (1:1,000 dilution; cat. no. 4348), anti-phospho-ERK1/2 (Thr202/Tyr204) (1:1,000 dilution; cat. no. 14227), anti-p38 (1:1,000 dilution; cat. no. 14451), anti-phospho-p38 (Thr180/Tyr182) (1:1,000 dilution; cat. no. 4092), anti-JNK (1:1,000 dilution; cat. no. 3708), anti-phospho-JNK (Thr183/Tyr185) (1:1,000 dilution; cat. no. 4671; all Cell Signaling Technology, Inc., Danvers, MA, USA), anti- $\beta$-actin (1:1,000 dilution; cat. no. SC-130300) and anti-MMP-1 (1:1,000 dilution; cat. no. SC-8836-R; both Santa Cruz Biotechnology Inc., Dallas, TX, USA). The bound antibodies were detected with the appropriate secondary antibodies (1:2,000 dilution; cat. nos. 7074, 7076 and 7077; Cell Signaling Technology, Inc.) and the protein bands were visualized with a 3,3'-diaminobenzidine staining kit (Beijing Zhongshan Goldenbridge Biotechnology Co., Ltd., Beijing, China). The bands were quantified using ImageJ 1.37 software (National Institutes of Health, Bethesda, MD, USA).

Immunostaining. Cells were plated on coverslips at a density of $2.0 \times 10^{5}$ cells per $35-\mathrm{mm}$ dish and grown for $48 \mathrm{~h}$ in growth medium. Coverslips containing cells were then incubated with $1 \mathrm{mg} / \mathrm{ml}$ Alexa Fluor 594-labeled cholera toxin subunit B (red; cat. no. C-34777; Thermo Fisher Scientific, Inc.) for $10 \mathrm{~min}$ on ice. Following incubation, cells were fixed with formalin, 
A
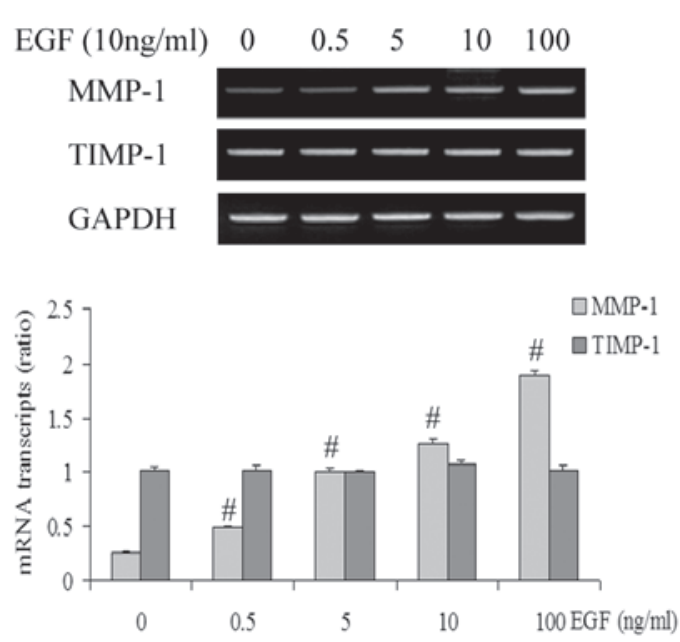

C

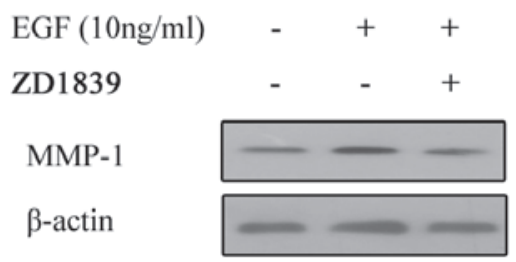

B EGF $(10 \mathrm{ng} / \mathrm{ml}) \quad 0 \quad 10 \mathrm{~m} 30 \mathrm{~m} \quad 1 \mathrm{~h} \quad 2 \mathrm{~h} \quad 4 \mathrm{~h} \quad 8 \mathrm{~h} \quad 24 \mathrm{~h}$
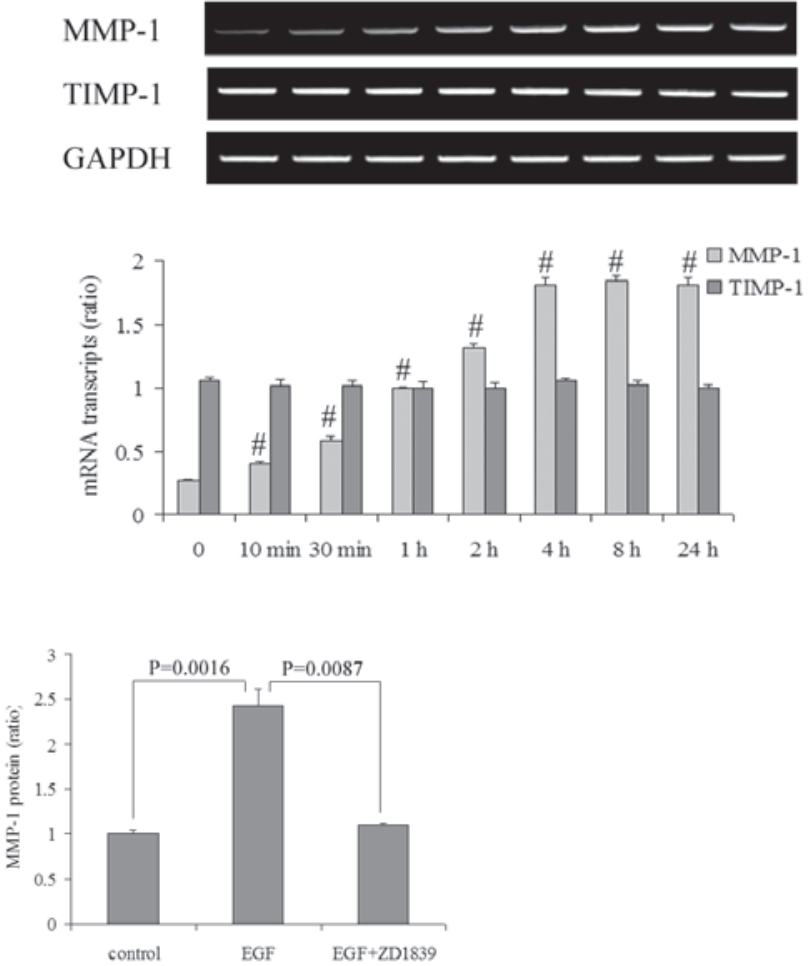

Figure 1. EGF increases MMP-1 expression but does not change TIMP-1 expression. Serum-deprived SiHa cells were incubated with (A) $0.5,5,10$ or $100 \mathrm{ng} / \mathrm{ml}$ EGF for $2 \mathrm{~h}$ or (B) with $10 \mathrm{ng} / \mathrm{ml}$ EGF for the lengths of time indicated. Total RNA was extracted and analyzed by RT-qPCR. The $\Delta \Delta C \mathrm{Cq}$ results of the RT-qPCR products (data are the mean of three independent experiments \pm SD) are shown as the ratio of MMP-1 and TIMP-1 to GAPDH mRNA in the bar graphs. ${ }^{\text {\#}} \mathrm{P}<0.05$ compared with control (non-stimulated) cells alone. (C) Serum-starved SiHa cells in the presence or absence of the EGFR inhibitor ZD1839 were incubated with $10 \mathrm{ng} / \mathrm{ml} \mathrm{EGF}$ for $24 \mathrm{~h}$, and the cell lysates were then analyzed by western blotting using anti-MMP-1 or anti- $\beta$-actin antibodies as probes. The laser densitometry results (the data are the mean of three independent experiments \pm SD) are shown in the bar graph as the ratio of MMP-1 to $\beta$-actin $(\mathrm{P}<0.05$; EGF vs. control; EGF+ZD1839 vs. EGF). The results shown are from representative experiments performed in triplicate. MMP, matrix metalloproteinase; EGF, epidermal growth factor; TIMP-1, tissue inhibitor of matrix metalloproteinase-1; SD, standard deviation; RT-qPCR, reverse transcription-quantitative polymerase chain reaction; mRNA, messenger RNA.

permeabilized with $0.1 \%$ Triton $\mathrm{X}-100$, blocked in $20 \%$ goat serum (Zhejiang Tianhang Biotechnology Co., Ltd.) for $1 \mathrm{~h}$ and incubated with anti-EGFR labeled with Alexa Fluor 488 (green; 1:100 dilution; cat. no. A-11008; Invitrogen; Thermo Fisher Scientific, Inc.) for $1 \mathrm{~h}$ at $37^{\circ} \mathrm{C}$. Nuclei were stained with DAPI (blue; Invitrogen; Thermo Fisher Scientific, Inc.). Imaging was performed via confocal microscopy using an Axioplan 2 Apotome microscope (Zeiss GmbH, Jena, Germany) fitted with a $63 \times 1.25$ oil immersion lens.

Adenoviral transfections. Cells were plated in 6-well plates at a density of 200,000 cells $/ \mathrm{ml}$ in triplicates for each condition. The pCMV adenoviruses constitutively active (CA)-MEK and dominant negative (DN)-MEK were purchased from Shanghai GenePharma Co., Ltd. (Shanghai, China). The cells were infected with recombinant adenoviruses to overexpress CA-MEK and DN-MEK at a multiplicity of infection of 25 for $48 \mathrm{~h}$. The medium was then aspirated and replaced with serum-free medium containing $\mathrm{M} \beta \mathrm{CD}(0.5 \mathrm{mM})$ for $1 \mathrm{~h}$. Upon incubation, the cells were treated with EGF (10 ng/ml) for $24 \mathrm{~h}$ before protein collection.

Statistical analyses. The data were presented as the mean \pm standard deviation and subjected to analysis of variance with the Student-Newman-Keuls test using the statistical software package SPSS 11.0 (SPSS Inc., Chicago, IL, USA). $\mathrm{P}<0.05$ was considered to indicate a statistically significant difference.

\section{Results}

EGF upregulates MMP-1 expression at the messenger RNA $(m R N A)$ and protein levels. It was previously demonstrated by the present authors that EGFR regulates MT1-MMP and MMP-2 synthesis in SiHa cells via both the PI3-K/AKT and MAPK/ERK pathways in SiHa cells (22). To further indicate a role for EGFR in the synthesis and function of other MMP members in SiHa cells, the changes in MMP-1 expression were investigated at the mRNA and protein levels following EGF treatment in the present study. The RT-qPCR results demonstrated that EGF induced an increase in MMP-1 mRNA in $\mathrm{SiHa}$ cells in a concentration-dependent manner $(\mathrm{P}<0.05$; Fig. 1A). Additional analysis revealed that the MMP-1 mRNA expression commenced to increase in response to $10 \mathrm{ng} / \mathrm{ml}$ EGF $(\mathrm{P}<0.05)$, and that it reached maximal levels at $4 \mathrm{~h}$ and remained high for $\leq 24 \mathrm{~h}$ (Fig. 1B). However, TIMP-1 mRNA levels remained unchanged by EGF $(\mathrm{P}>0.05)$. Furthermore, increased MMP-1 mRNA synthesis was reflected in increased protein levels $(\mathrm{P}<0.05)$ that were detectable $24 \mathrm{~h}$ after $\mathrm{EGF}$ regulation (Fig. 1C). 
A Lipid Raft Fractions

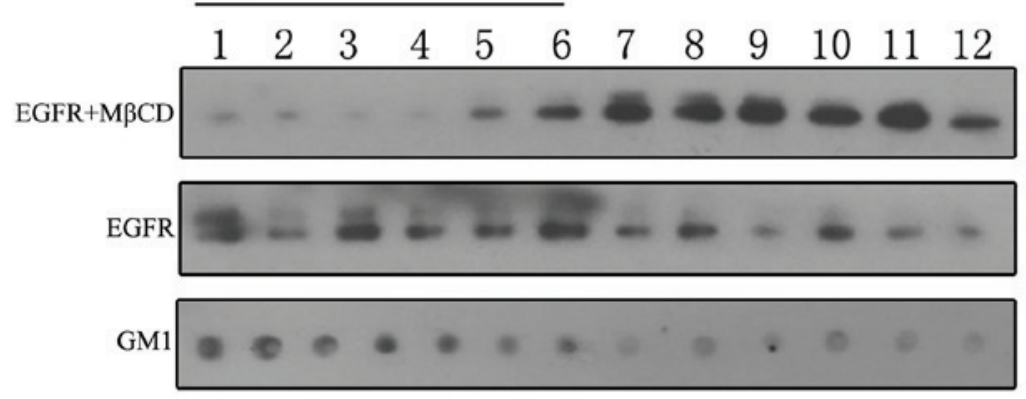

B

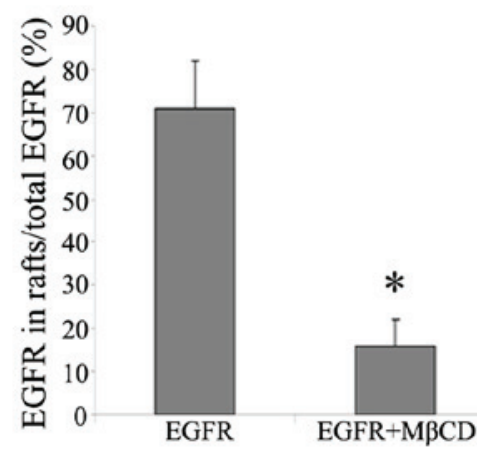

C
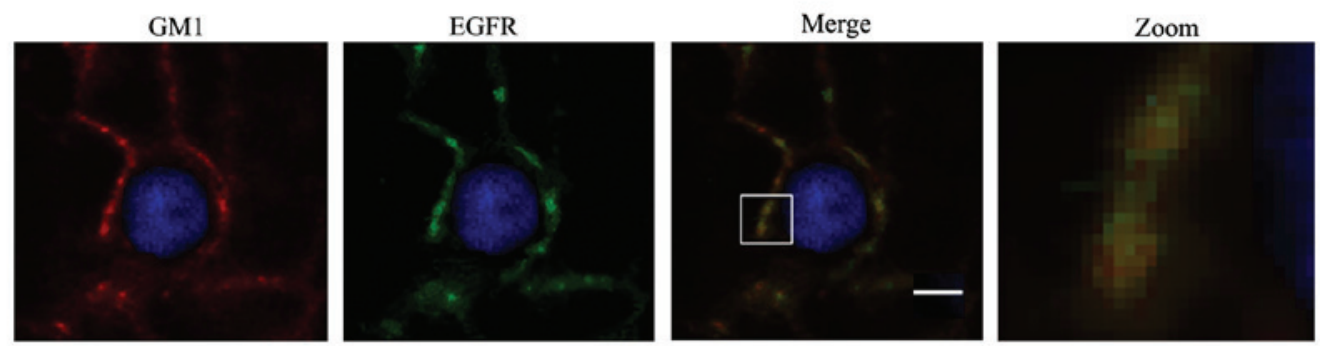

Figure 2. EGFR localizes to lipid rafts in SiHa cells. (A) Cells (1-2x106) were plated and cultured for $72 \mathrm{~h}$. Detergent-free lysis was performed, and lipid rafts were separated by ultracentrifugation. Western blotting was performed for EGFR, and fractions were dot blotted for GM1 utilizing cholera toxin subunit B-horseradish peroxidase. Fractions 1-6 contain lipid rafts. Blots are representative of $\geq 3$ independent experiments. (B) Densitometry was performed on western blot images from panel A. Bars represent the percentage of EGFR in lipid raft fractions (1-6) compared with the total amount of EGFR present (fractions 1-12) from $\geq 3$ independent experiments. Statistical analyses were performed utilizing the Student's $t$ test ("P<0.05 compared with cells without M $\beta C D$ treatment). (C) Cells $(200,000)$ were plated onto coverslips and cultured for $48 \mathrm{~h}$. Cells were incubated with Alexa Fluor 594-labeled cholera toxin subunit B at $1 \mathrm{mg} / \mathrm{ml}$ for $10 \mathrm{~min}$ on ice prior to fixation. Cells were then fixed, blocked in $20 \%$ goat serum, and incubated with immunofluorescent anti-EGFR antibodies (green). Nuclei were stained with DAPI (blue). Imaging was performed using a Zeiss Axioplan 2 Apotome microscope fitted with a $63 \times 1.25$ oil immersion lens. Magnified views of the boxed area are shown in the bottom panels. Scale bars represent a distance of $5 \mu \mathrm{m}$. Images are representative of $\geq 3$ independent experiments. EGFR, epidermal growth factor receptor; $\mathrm{M} \beta \mathrm{CD}$, methyl- $\beta$-cyclodextrin; GM1, monosialotetrahexosylganglioside.

To demonstrate that EGFR activation by EGF specifically regulates MMP-1 expression, the activation of EGFR was inhibited using the small molecule inhibitor ZD1839. Addition of ZD1839 (10 nM) $1 \mathrm{~h}$ prior to treatment with EGF completely inhibited the EGF-induced increase in MMP-1 at the protein level $(\mathrm{P}<0.05$; Fig. 1C).

EGFR localizes to lipid rafts in SiHa cells. Previous studies have shown that EGFR localizes to lipid rafts in CHO and HeLa cells (24). To determine whether EGFR localizes specifically to lipid rafts in SiHa cells, two methods were used to identify these structures: Biochemical raft isolation and confocal microscopy. First, a detergent-free Opti-Prep gradient was used to isolate lipid rafts (26). Dot blotting for the lipid raft-specific glycosphingolipid GM1 identified fractions 1-6 as lipid raft fractions. When these fractions were immunoblotted using anti-EGFR antibodies, EGFR localization to lipid raft fractions was observed to be most prominent in SiHa cells. When M $\beta C D$, a cytotoxic cholesterol-sequestering agent, was used to pharmacologically deplete cholesterol from the cells, the protein levels of EGFR were decreased in the lipid raft fractions (Fig. 2A). Quantitative analysis demonstrated that the lipid raft fractions contained significantly more EGFR compared with the non-lipid raft fractions in $\mathrm{SiHa}$ cells $(\mathrm{P}<0.05$; Fig. 2B). Cells were stained with Alexa Fluor 488-labeled anti-EGFR antibodies (green) and Alexa Fluor 594-labeled cholera toxin subunit B (red), which binds specifically to GM1 (27), to detect localization of lipid rafts. Using confocal microscopy, it was observed that EGFR (green) co-localized (yellow/orange) with GM1 (red) at the plasma membrane of SiHa cells (Fig. 2C). Taken together, these data suggested that EGFR localizes within lipid rafts in SiHa cells.

Lipid raft disruption reinforces EGFR-induced upregulation of $M M P-1$ expression. As previously reported, lipid raft localization of EGFR inhibits ligand binding in certain types of cancers, and lipid rafts promote EGFR signaling in other types of cancer (19-21). Since it was noticed that EGFR localizes to lipid rafts in SiHa cells, the present study examined whether the redistribution of EGFR induced by lipid raft disruption reinforces the EGFR-induced upregulation of MMP-1 expression in SiHa cells. Lipid raft disruption by $\mathrm{M} \beta \mathrm{CD}$ enhanced the EGF-induced increase in MMP-1 synthesis at both the mRNA and protein levels $(\mathrm{P}<0.05)$, and cholesterol post-treatment reversed this change. To investigate whether EGFR activation by lipid raft disruption specifically regulates MMP-1 expression, the activation of EGFR was inhibited with ZD1839. The results revealed that ZD1839 completely inhibited the MBCD-reinforced MMP-1 synthesis induced by EGF at both the mRNA and protein levels (Fig. 3). These data indicate that lipid raft localization of EGFR inhibits EGFR-induced upregulation of MMP-1 expression.

MAPK/ERK signaling is involved in the regulation of MMP-1 expression. Localization of EGFR to lipid rafts has variable 

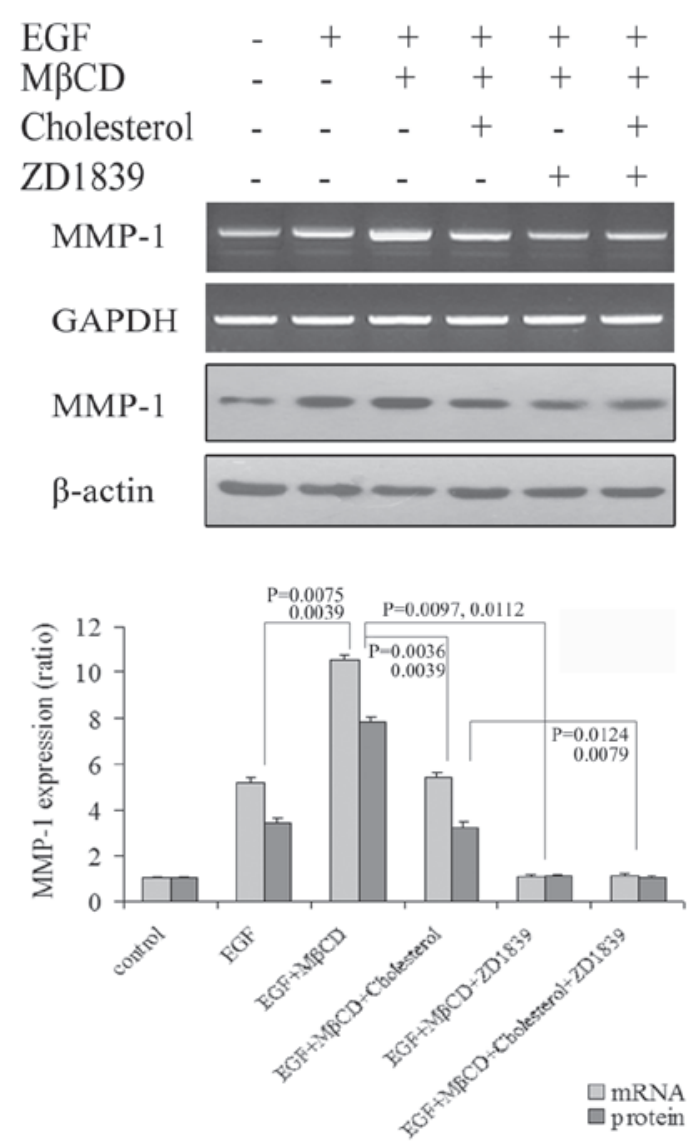

Figure 3. Lipid raft disruption reinforces EGFR-induced upregulation of MMP-1 expression. Serum-deprived SiHa cells were treated with $10 \mathrm{ng} / \mathrm{ml}$ EGF in the presence or absence of M $\beta C D$, cholesterol and ZD1839 for $1 \mathrm{~h}$ before exposure to EGF. Total RNA was extracted $2 \mathrm{~h}$ later and then analyzed by reverse transcription-quantitative polymerase chain reaction, in which the MMP-1 or GAPDH mRNA levels were measured. Cell lysates were analyzed $24 \mathrm{~h}$ later by western blotting, in which anti-MMP-1 or anti- $\beta$-actin antibodies were used as probes. The laser densitometry results (the data are the mean of three independent experiments \pm standard deviation) are shown in the bar graph, and are expressed as a ratio. MMP, matrix metalloproteinase EGF, epidermal growth factor; $M \beta C D$, methyl- $\beta$-cyclodextrin; mRNA, messenger RNA.

effects on signaling pathways downstream of EGFR (19-21). Thus, the effect of cholesterol depletion on EGFR signaling was examined in SiHa cells. Cells were treated with $\mathrm{M} \beta \mathrm{CD}$, and western blotting was performed to determine whether EGFR induced the phosphorylation of key mediators, including AKT, MAPK, p38 and JNK. As expected, lipid raft disruption resulted in increased AKT, MAPK, p38 and JNK phosphorylation, while cholesterol addition abrogated the $\mathrm{M} \beta \mathrm{CD}$-induced increase in phosphorylation of these kinases (Fig. 4A). To determine the downstream EGFR signaling pathways involved in the increase of MMP-1 expression, $\mathrm{SiHa}$ cells were treated with selective PI3-K inhibitors (LY294002 or wortmannin), MEK inhibitors (PD98059 or U0126), a p38 inhibitor (SB203580) or a JNK inhibitor (SP600125) for $2 \mathrm{~h}$ before the addition of EGF. The results demonstrated that treatment of SiHa cells with PD98059 or U0126 reduced MMP-1 mRNA expression, which was mediated by both EGF and M $\beta C D(P<0.05)$. By contrast, application of LY294002, wortmannin, SB203580 or SP600125 had no effect on MMP-1
mRNA synthesis $(\mathrm{P}>0.05)$. Western blot analysis revealed that the impact of these inhibitors on MMP-1 mRNA synthesis induced by both EGF and M $\beta C D$ was similar to the impact on MMP-1 protein synthesis $(\mathrm{P}<0.05$; Fig. 4B). To more closely examine the involvement of the MAPK signaling pathway in the induction of MMP-1 by both EGF and M $\beta C D$, adenoviral constructs targeting MEK were employed. The levels of phospho-ERK1/2, total ERK1/2 and MMP-1 were examined following transfection of $\mathrm{SiHa}$ cells with a CA-MEK adenoviral construct (Ad-CA-MEK), a DN-MEK adenoviral construct (Ad-DN-MEK) or pCMV control. In the presence of DN-MEK, the phospho-ERK and MMP-1 levels were reduced. In contrast, MMP-1 protein expression was increased in cells transfected with the CA-MEK construct (Fig. 4C). These results indicated that the MAPK/ERK signaling pathway is involved in the regulation of MMP-1 expression by lipid raft disruption.

\section{Discussion}

The present study provides evidence describing a role for lipid rafts in the resistance to EGFR-induced MMP-1 expression in SiHa cells. The results demonstrated that EGFR activation by EGF specifically regulates MMP-1 expression at the mRNA and protein levels. Additionally, the current study provided evidence that EGFR localizes to lipid rafts in SiHa cells. In our study, $\mathrm{M} \beta \mathrm{CD}$, a cytotoxic cholesterol-sequestering agent that pharmacologically depletes cholesterol from the cells, decreased EGFR protein levels in lipid raft fractions. Importantly, redistribution of EGFR induced by lipid raft disruption altered MMP-1 expression levels. Furthermore, lipid raft disruption resulted in increased phosphorylation of AKT, MAPK, p38 and JNK. Thus, the MAPK/ERK signaling pathway may be involved in the regulation of MMP-1 expression. Our data suggest that lipid rafts provide a platform to inhibit EGFR regulation of MMP-1 in SiHa cells through the MAPK/ERK signaling pathway.

Invasion and distant metastasis are important events that affect the prognosis and treatment of cervical cancer patients (28). Patients in the later stages of cervical cancer with invasion or metastasis have a significantly worse prognosis (29). Fewer than $20 \%$ of women with stage IV cervical cancer survive for $\geq 5$ years (30). Thus, understanding the molecular and cellular mechanisms of cell invasion and metastasis is critical for developing effective cervical cancer therapies and improving patient survival. Cell invasion and metastasis have been associated primarily with degradation of ECM components $(26,31)$. MMP-1 is important in malignant processes of cervical cancer (32). Furthermore, it has become increasingly clear in the past years that MMP-1 substrates extend to numerous non-matrix extracellular and membrane-bound proteins, including protease precursors, protease inhibitors, cytokines, latent growth factors, growth factor-binding proteins and adhesion molecules $(9,10,33)$. Thus, understanding how MMP-1 is regulated in cervical cancer may be crucial for developing more effective therapies for metastatic cancer. The present study examined the influence of EGFR in the regulation of MMP-1 expression. By perturbing EGFR using EGF stimulation in SiHa cervical cancer cells, MMP-1 synthesis was increased. In the same 
A

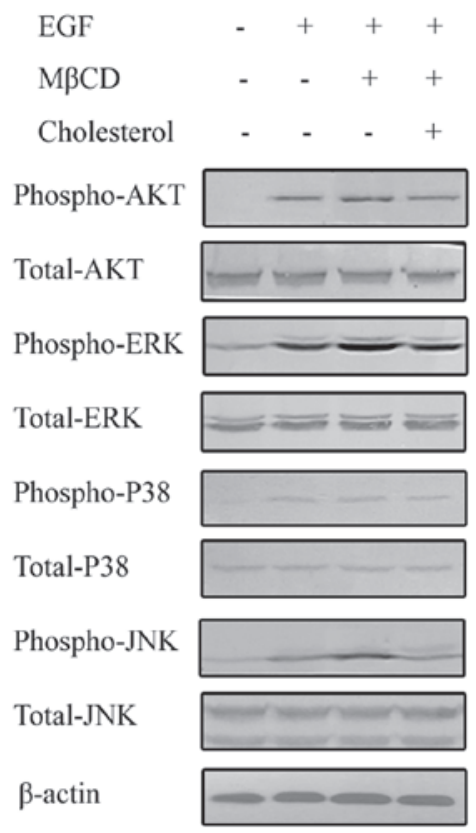

C
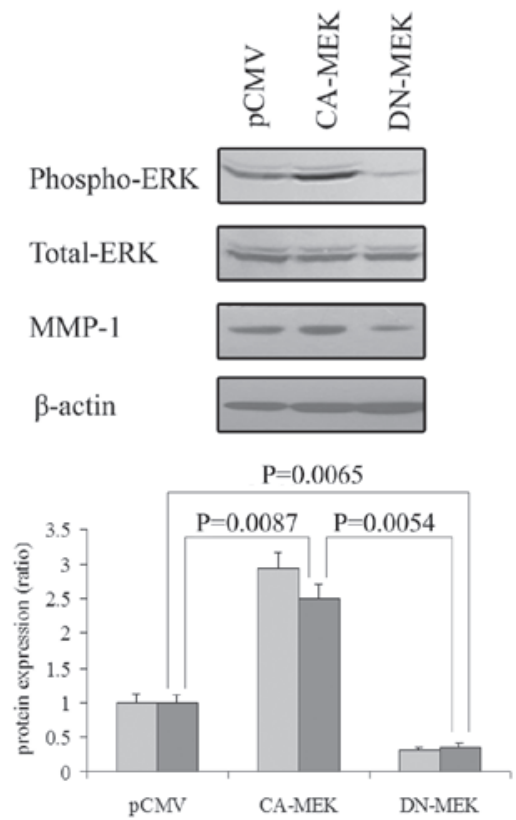

B
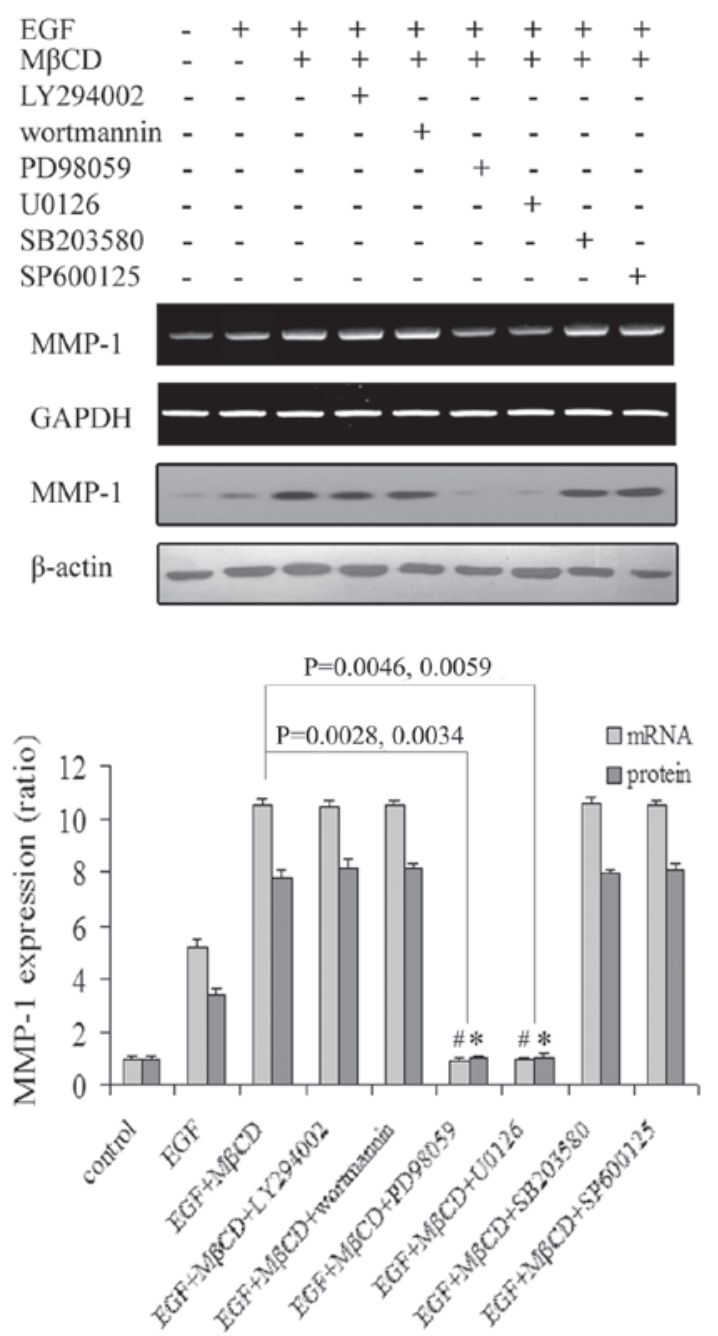

$\square$ Phospho-ERK

$\square \mathrm{MMP}-1$

Figure 4. The MAPK/ERK signaling pathway is involved in the regulation of MMP-1 expression. (A) Serum-deprived SiHa cells were incubated for $1 \mathrm{~h}$ in the presence or absence of $\mathrm{M} \beta \mathrm{CD}$ and cholesterol, and were then incubated with $10 \mathrm{ng} / \mathrm{ml}$ EGF for $2 \mathrm{~h}$. The cell lysates were analyzed by western blotting with anti-AKT, anti-phospho-AKT, anti-ERK1/2, anti-phospho-ERK1/2, anti-p38, anti-phospho-p38, anti-JNK, anti-phospho-JNK and anti- $\beta$-actin antibodies. The results shown are from representative experiments performed in triplicate. (B) Serum-deprived SiHa cells were incubated with $10 \mathrm{ng} / \mathrm{ml}$ EGF in the presence of the corresponding pharmacological inhibitors for $1 \mathrm{~h}$ before exposure to EGF. Total RNA was extracted $2 \mathrm{~h}$ later and then analyzed by reverse transcription-quantitative polymerase chain reaction, in which the MMP-1 or GAPDH mRNA levels were measured. Cell lysates were analyzed $24 \mathrm{~h}$ later by western blotting, in which anti-MMP-1 or anti- $\beta$-actin antibodies were used as probes. The laser densitometry results (the data are the mean of three independent experiments $\pm \mathrm{SD}$ ) are shown in the bar graph and are expressed as a ratio. ${ }^{\#} \mathrm{P}<0.05$ compared with EGF-stimulated cells with $\mathrm{M} \beta C D$ treatment. ${ }^{*} \mathrm{P}<0.05$ compared with EGF-stimulated cells with $\mathrm{M} \beta \mathrm{CD}$ treatment. (C) Cells were infected with recombinant adenoviruses for expression of CA-MEK and DN-MEK for $48 \mathrm{~h}$, and then treated with EGF $(10 \mathrm{ng} / \mathrm{ml})$ for $24 \mathrm{~h}$ in the absence of M $\beta C D$ treatment for $1 \mathrm{~h}$ before exposure to EGF. Cell lysates were analyzed by western blotting, in which anti-ERK1/2, anti-phospho-ERK1/2, anti-MMP-1 or anti- $\beta$-actin antibodies were used as probes. The laser densitometry results (the data are the mean of three independent experiments \pm SD) are shown in the bar graphs and are expressed as a ratio. P<0.05 compared with each other. Phospho, phosphorylated; MMP, matrix metalloproteinase; EGF, epidermal growth factor; $\mathrm{M} \beta \mathrm{CD}$, methyl- $\beta$-cyclodextrin; mRNA, messenger RNA; ERK, extracellular signal-regulated kinase; JNK, c-Jun N-terminal kinase; MAPK, mitogen-activated protein kinase; MEK, MAPK kinase; CA, constitutively active; DN, dominant negative; SD, standard deviation.

model system, inhibition of EGFR by ZD1839 led to decreased MMP-1 levels.

Cervical carcinoma is associated primarily with high-risk human papillomaviruses (HR-HPVs), including HPV-16 and
HPV-18, which encode the E6 and E7 oncogenes (34). The E6 and E7 proteins are considered to immortalize cervical epithelial cells by interfering with the function of the tumor suppressor proteins p53 and retinoblastoma protein, 
respectively (35). The expression of HR-HPV E6 has been linked to an increase in EGFR levels $(13,36)$, and changes in the functional levels of the HPV E6/E7 proteins may alter the growth rate of cervical cancer cell lines by reducing the stability of EGFR at the post-transcriptional level (37). Thus, it is reasonable to infer that E6/E7 proteins could upregulate the expression of MMP-1 by inducing high levels of EGFR in $\mathrm{SiHa}$ cells.

The present data indicate that the localization of EGFR specifically to lipid rafts contributes to the inhibition of the EGFR-induced MMP-1 expression in SiHa cells. EGFR co-localizes with lipid rafts in SiHa cells, and the lipid environment of EGFR-overexpressing cells influences the dimerization properties and signaling functions of EGFR (38). Of note, the 3-hydroxy-3-methyl-glutaryl-coenzyme A-reductase inhibitor statin has been commonly used to deplete cells of lipid rafts for various years (39). Preclinical data have demonstrated that lipid raft depletion by statins can reduce cell growth and sensitize cells to apoptotic stimuli in a number of cancers, including prostate, melanoma and EGFR-overexpressing breast cancer $(40,41)$. Epidemiologic data have demonstrated that the use of statins as single agents in breast cancer is beneficial $(42,43)$. Furthermore, in vitro studies combining statins along with other therapies suggest that statins may have a greater clinical benefit when used as part of combinatorial therapies (39). However, the present results indicated that cholesterol depletion synergizes with the activation of EGFR and results in increased phosphorylation of AKT, MAPK, p38 and JNK. It is well known that the activation of two downstream pathways of EGFR, the Ras/Raf/MAPK/ERK pathway and the PI3-K/AKT pathway, can induce cell proliferation and decrease cell apoptosis (44). Importantly, the mechanism of action of statin drugs is not solely through the reduction of cholesterol but also via the inhibition of geranylgeranylated and farnesylated small GTPases, which suppress the activation of small $\mathrm{G}$ proteins (45). Therefore, it is difficult to infer whether statins would be beneficial as a part of cervical cancer therapies.

The associations between different signaling pathways and MMPs have been investigated in a number of cell culture systems (46-48). Using selective pharmaceutical inhibitors of EGFR downstream signaling pathway effectors, the present study revealed that MMP-1 expression was upregulated through the MAPK/ERK signaling pathway in SiHa cells treated with EGF and M $\beta C D$, and that the PI3-K/AKT, p38 MAPK and JNK/MAPK signaling pathways were not involved in this process. These observations were further supported by the fact that the transfection of MEK-CA led to increased ERK phosphorylation and MMP-1 levels, as well as the fact that the transfection of MEK-DN abolished the basal expression of MMP-1. However, our previous studies indicated that EGFR upregulates MT1-MMP and downregulates MMP-2 through the MAPK/ERK pathway, while concomitantly transmitting a mild positive regulatory signal to the expression of MMP-2 via the PI3-K/AKT pathway in SiHa cells (22). Thus, the signaling pathways involved in the regulation of different MMPs by EGFR are varied.

In conclusion, the present study demonstrated that lipid raft localization of EGFR repressed EGFR-induced MMP-1 expression in SiHa cells, and that the MAPK/ERK signaling pathway was involved in this process. Since MMP-mediated ECM remodeling and invasion of tumors are tightly linked, the regulation of MMP-1 may contribute to the central role that EGFR and lipid rafts have in the development and metastasis of cervical cancer. However, the data presented herein were based on in vitro experiments; thus, additional in vivo studies are required to obtain a better understanding of MMP-1 involvement in cervical tumorigenesis. Experiments focusing on manipulating MMP-1 expression using an in vivo model are in progress and will provide further information regarding the influence of MMP-1 on cervical carcinomas.

\section{Acknowledgements}

The present study was supported by the Natural Science Foundation of Heilongjiang Province (Harbin, China; grant no. 200906), the Foundation of Heilongjiang Provincial Educational Department (Harbin, China; grant no. 11551163) and the Foundation of Heilongjiang Provincial Health Department (Harbin, China; grant no. 2009-112).

\section{References}

1. Jemal A, Bray F, Center MM, Ferlay J, Ward E and Forman D: Global cancer statistics. CA Cancer J Clin 61: 69-90, 2011.

2. Pei D: Matrix metalloproteinases target protease-activated receptors on the tumor cell surface. Cancer Cell 7: 207-208, 2005.

3. Pittayapruek P, Meephansan J, Prapapan O, Komine M and Ohtsuki M: Role of Matrix Metalloproteinases in Photoaging and Photocarcinogenesis. Int J Mol Sci 17: 868, 2016.

4. Poola I, DeWitty RL, Marshalleck JJ, Bhatnagar R, Abraham J and Leffall LD: Identification of MMP-1 as a putative breast cancer predictive marker by global gene expression analysis. Nat Med 11: 481-483, 2005.

5. Yang R, Xu Y, Li P, Zhang X, Wang J, Gu D and Wang Y: Combined upregulation of matrix metalloproteinase-1 and proteinase-activated receptor-1 predicts unfavorable prognosis in human nasopharyngeal carcinoma. Onco Targets Ther 6: 1139-1146, 2013

6. Guan X, Wang X, Luo H, Wu J, Zhang X and Wu J: Matrix metalloproteinase 1, 3 and 9 polymorphisms and esophageal squamous cell carcinoma risk. Med Sci Monit 20: 2269-2274, 2014.

7. Botta GP, Reginato MJ, Reichert M, Rustgi AK and Lelkes PI: Constitutive K-RasG12D activation of ERK2 specifically regulates 3D invasion of human pancreatic cancer cells via MMP-1. Mol Cancer Res 10: 183-196, 2012.

8. Cai QW, Li J, Li XQ, Wang JQ and Huang Y: Expression of STAT3, MMP-1 and TIMP-1 in gastric cancer and correlation with pathological features. Mol Med Rep 5: 1438-1442, 2012.

9. Liu H, Kato Y, Erzinger SA, Kiriakova GM, Qian Y, Palmieri D, Steeg PS and Price JE: The role of MMP-1 in breast cancer growth and metastasis to the brain in a xenograft model. BMC Cancer 12: 583, 2012.

10. Hua H, Li M, Luo T, Yin Y and Jiang Y: Matrix metalloproteinases in tumorigenesis: An evolving paradigm. Cell Mol Life Sci 68: 3853-3868, 2011.

11. Iida J and McCarthy JB: Expression of collagenase-1 (MMP-1) promotes melanoma growth through the generation of active transforming growth factor-beta. Melanoma Res 17: 205-213, 2007.

12. Ma D, Hovey RL, Zhang Z, Fye S, Huettner PC, Borecki IB and Rader JS: Genetic variations in EGFR and ERBB4 increase susceptibility to cervical cancer. Gynecol Oncol 131: 445-450, 2013.

13. Schrevel M, Gorter A, Kolkman-Uljee SM, Trimbos JB, Fleuren GJ and Jordanova ES: Molecular mechanisms of epidermal growth factor receptor overexpression in patients with cervical cancer. Mod Pathol 24: 720-728, 2011.

14. Wagner EF and Nebreda AR: Signal integration by JNK and p38 MAPK pathways in cancer development. Nat Rev Cancer 9: 537-549, 2009. 
15. Sadowski L, Pilecka I and Miaczynska M: Signaling from endosomes: Location makes a difference. Exp Cell Res 315: 1601-1609, 2009.

16. Guéguinou M, Gambade A, Félix R, Chantôme A, Fourbon Y, Bougnoux P, Weber G, Potier-Cartereau $M$ and Vandier C: Lipid rafts, $\mathrm{KCa} / \mathrm{ClCa} / \mathrm{Ca} 2+$ channel complexes and EGFR signaling: Novel targets to reduce tumor development by lipids? Biochim Biophys Acta 1848: 2603-2620, 2015.

17. Staubach S and Hanisch FG: Lipid rafts: Signaling and sorting platforms of cells and their roles in cancer. Expert Rev Proteomics 8: 263-277, 2011.

18. Mollinedo F and Gajate C: Lipid rafts as major platforms for signaling regulation in cancer. Adv Biol Regul 57: 130-146, 2015.

19. Chen X and Resh MD: Cholesterol depletion from the plasma membrane triggers ligand-independent activation of the epidermal growth factor receptor. J Biol Chem 277: 49631-49637, 2002.

20. Roepstorff K, Thomsen P, Sandvig K and van Deurs B: Sequestration of epidermal growth factor receptors in non-caveolar lipid rafts inhibits ligand binding. J Biol Chem 277: 18954-18960, 2002.

21. Irwin ME, Bohin N and Boerner JL: Src family kinases mediate epidermal growth factor receptor signaling from lipid rafts in breast cancer cells. Cancer Biol Ther 12: 718-726, 2011

22. Zhang Z, Song T, Jin Y, Pan J, Zhang L, Wang L and Li P: Epidermal growth factor receptor regulates MT1-MMP and MMP-2 synthesis in SiHa cells via both PI3-K/AKT and MAPK/ERK pathways. Int J Gynecol Cancer 19: 998-1003, 2009.

23. Pugniere P, Banzet $\mathrm{S}$, Chaillou T, Mouret $\mathrm{C}$ and Peinnequin A: Pitfalls of reverse transcription quantitative polymerase chain reaction standardization: Volume-related inhibitors of reverse transcription. Anal Biochem 415: 151-157, 2011.

24. Macdonald JL and Pike LJ: A simplified method for the preparation of detergent-free lipid rafts. J Lipid Res 46: 1061-1067, 2005

25. Zhang D and Brodt P: Type 1 insulin-like growth factor regulates MT1-MMP synthesis and tumor invasion via PI 3-kinase/Akt signaling. Oncogene 22: 974-982, 2003.

26. Egeblad M and Werb Z: New functions for the matrix metalloproteinases in cancer progression. Nat Rev Cancer 2: 161-174, 2002

27. Janes PW, Ley SC and Magee AI: Aggregation of lipid rafts accompanies signaling via the $\mathrm{T}$ cell antigen receptor. J Cel Biol 147: 447-461, 1999

28. Zhou X, Xu CJ, Wang JX, Dai T, Ye YP, Cui YM, Liao WT, Wu XL and Ou JP: Metastasis-Associated in Colon Cancer-1 Associates With Poor Prognosis and Promotes Cell Invasion and Angiogenesis in Human Cervical Cancer. Int J Gynecol Cancer 25: 1353-1363, 2015.

29. Lee JY, Lee C, Hahn S, Kim MA, Kim HS, Chung HH, Kim JW, Park NH and Song YS: Prognosis of adenosquamous carcinoma compared with adenocarcinoma in uterine cervical cancer: A systematic review and meta-analysis of observational studies. Int J Gynecol Cancer 24: 289-294, 2014.

30. Song C, Zhu S, Wu C and Kang J: Histone deacetylase (HDAC) 10 suppresses cervical cancer metastasis through inhibition of matrix metalloproteinase (MMP) 2 and 9 expression. J Biol Chem 288: 28021-28033, 2013.

31. Bonnans C, Chou J and Werb Z: Remodelling the extracellular matrix in development and disease. Nat Rev Mol Cell Biol 15 786-801, 2014

32. Lai HC, Chu CM, Lin YW, Chang CC, Nieh S, Yu MH and Chu TY: Matrix metalloproteinase 1 gene polymorphism as a prognostic predictor of invasive cervical cancer. Gynecol Oncol 96: 314-319, 2005.
33. McCawley LJ and Matrisian LM: Matrix metalloproteinases: They're not just for matrix anymore! Curr Opin Cell Biol 13: 534-540, 2001

34. Tan S, de Vries EG, van der Zee AG and de Jong S: Anticancer drugs aimed at E6 and E7 activity in HPV-positive cervical cancer. Curr Cancer Drug Targets 12: 170-184, 2012.

35. Saha SK and Khuda-Bukhsh AR: Berberine alters epigenetic modifications, disrupts microtubule network, and modulates HPV-18 E6-E7 oncoproteins by targeting p53 in cervical cancer cell HeLa: A mechanistic study including molecular docking. Eur J Pharmacol 744: 132-146, 2014.

36. Soonthornthum T, Arias-Pulido H, Joste N, Lomo L, Muller C, Rutledge $\mathrm{T}$ and Verschraegen $\mathrm{C}$ : Epidermal growth factor receptor as a biomarker for cervical cancer. Ann Oncol 22: 2166-2178, 2011

37. Mathur RS and Mathur SP: Vascular endothelial growth factor (VEGF) up-regulates epidermal growth factor receptor (EGF-R) in cervical cancer in vitro: This action is mediated through HPV-E6 in HPV-positive cancers. Gynecol Oncol 97: 206-213, 2005.

38. Suprynowicz FA, Disbrow GL, Krawczyk E, Simic V, Lantzky K and Schlegel R: HPV-16 E5 oncoprotein upregulates lipid raft components caveolin-1 and ganglioside GM1 at the plasma membrane of cervical cells. Oncogene 27: 1071-1078, 2008.

39. Irwin ME, Mueller KL, Bohin N, Ge Y and Boerner JL: Lipid raft localization of EGFR alters the response of cancer cells to the EGFR tyrosine kinase inhibitor gefitinib. J Cell Physiol 226: 2316-2328, 2011

40. Roy M, Kung HJ and Ghosh PM: Statins and prostate cancer: Role of cholesterol inhibition vs. prevention of small GTP-binding proteins. Am J Cancer Res 1: 542-561, 2011.

41. Herrero-Martin G and López-Rivas A: Statins activate a mitochondria-operated pathway of apoptosis in breast tumor cells by a mechanism regulated by ErbB 2 and dependent on the prenylation of proteins. FEBS Lett 582: 2589-2594, 2008

42. Kwan ML, Habel LA, Flick ED, Quesenberry CP and Caan B: Post-diagnosis statin use and breast cancer recurrence in a prospective cohort study of early stage breast cancer survivors. Breast Cancer Res Treat 109: 573-579, 2008.

43. Cardwell CR, Hicks BM, Hughes C and Murray LJ: Statin use after diagnosis of breast cancer and survival: A population-based cohort study. Epidemiology 26: 68-78, 2015.

44. Zhang Y, Wang L, Zhang M, Jin M, Bai C and Wang X: Potential mechanism of interleukin-8 production from lung cancer cells: An involvement of EGF-EGFR-PI3K-Akt-Erk pathway. J Cell Physiol 227: 35-43, 2012.

45. Vallianou NG, Kostantinou A, Kougias M and Kazazis C: Statins and cancer. Anticancer Agents Med Chem 14: 706-712, 2014.

46. Hsieh SC, Tsai JP, Yang SF, Tang MJ and Hsieh YH: Metformin inhibits the invasion of human hepatocellular carcinoma cells and enhances the chemosensitivity to sorafenib through a downregulation of the ERK/JNK-mediated NF- $\kappa \mathrm{B}$-dependent pathway that reduces uPA and MMP-9 expression. Amino Acids 46: 2809-2822, 2014

47. Wang F, Ke ZF, Wang R, Wang YF, Huang LL and Wang LT: Astrocyte elevated gene-1 (AEG-1) promotes osteosarcoma cell invasion through the JNK/c-Jun/MMP-2 pathway. Biochem Biophys Res Commun 452: 933-939, 2014.

48. Liu B, Li G, Wang X and Liu Y: A furin inhibitor downregulates osteosarcoma cell migration by downregulating the expression levels of MT1-MMP via the Wnt signaling pathway. Oncol Lett 7: 1033-1038, 2014. 